\title{
ESTUDO DE CASO: PROPOSTA DE SOLUÇÃO PARA TRATAMENTO INDIVIDUAL DE \\ ESGOTO SANITÁRIO EM UM LOTEAMENTO EM CAÇADOR
}

Cristiane Wegner ${ }^{1}$

Gabriela Cassol ${ }^{2}$

\section{RESUMO}

O sistema de esgotamento sanitário em locais desprovidos de rede coletora de esgotos é comumente abrangido por alternativas técnicas simplificadas que ofereçam condições satisfatórias para tratamento e disposição final de esgotos. Sua relevância é oriunda da melhora nas condições ambientais e sanitárias às quais a população de uma região está exposta, evitando a propagação de doenças e outros agravos ambientais. Este trabalho apresenta, em seu referencial teórico, as opções disponíveis de sistemas individuais de tratamento e disposição de esgoto sanitário, caracterizando as mais utilizadas, e expõe a situação encontrada no Loteamento Mantovani, cujo subsolo exige aplicações diferenciadas de tratamento. Além disso, demonstra a determinação e dimensionamento da solução individual adequada aos lotes deste loteamento residencial em Caçador, Santa Catarina, que consiste na adoção de tanque séptico para tratamento, filtro anaeróbio de fluxo ascendente para pós-tratamento, e valas de infiltração ou sumidouro para disposição final, de acordo com as características das edificações que serão executadas em cada lote.

Palavras-Chave: Tratamento de esgoto. Sistema individual. Esgoto residencial.

\section{ABSTRACT}

The sanitary sewage system in places deprived of sewer network is commonly covered by simplified technical alternatives that offer satisfactory conditions for treatment and final disposal of sewage. Its relevance comes from the improvement of environmental and health conditions to which the population of a region are

\footnotetext{
${ }^{1}$ Acadêmica do Curso de Engenharia Civil da Universidade Alto Vale do Rio do Peixe (UNIARP).

2 Professora Orientadora. Graduada em Engenharia Civil pela Universidade do Oeste de Santa Catarina (UNOESC), Mestre em Engenharia Civil pela Universidade Estadual Paulista (UNESP) e docente do Curso de Engenharia Civil da Universidade Alto Vale do Rio do Peixe.
} 
exposed, preventing the spread of diseases and other environmental damages. This paper presents in its theoretical reference the avaliable options of individual sanitary sewage treatment and disposal systems, characterizing the most used ones, and exposes the situation found at Loteamento Mantovani, in which the subsoil requires differentiated treatment applications. Besides, the essay demonstrates the determination and it sizes an appropriate solution for the building lot at this residential subdivision located in Caçador, Santa Catarina, consisting in using septic tank for treatment, upflow anaerobic filter for after treatment, and infiltration ditches or sewer sinkhole for final disposal, according to the buildings characteristics that will be implementated at each building lot.

Keywords: Sewage treatment. Individual system. Residential sewage.

\section{INTRODUÇÃO}

Responsável por inúmeros problemas de saúde pública, como o surgimento de doenças e a poluição, o tratamento de esgoto sanitário permanece pendente em grande parte dos municípios brasileiros (AISSE, 2000). Em áreas urbanas, suburbanas ou rurais, a ausência de serviços públicos de esgotos sanitários, seja ela parcial ou total, exige a implantação de algum método de disposição dos esgotos locais, visando evitar a contaminação da água e do solo. A defasagem na implantação de serviços públicos de saneamento em relação ao crescimento populacional permite prever a ampla adoção de soluções individuais para o destino de esgotos, principalmente nos países em desenvolvimento (JORDÃO; PESSOA, 1995).

Andrade Neto (1997) diz que não há um sistema de tratamento de esgotos que possa ser indicado como a melhor proposta para quaisquer condições, mas que a busca por uma solução que se adapte às condições locais e aos objetivos de cada caso proporciona uma melhor relação custo/benefício.

O Loteamento Mantovani, localizado no Município de Caçador, necessita de soluções alternativas à rede de esgotamento sanitário convencional, visto que esta, apesar de instalada, não poderá ser posta em operação até que a cidade possua capacidade de coletar este efluente por uma rede municipal. Assim, através da necessidade de coleta e disposição do esgoto gerado, considerando que a região é caracterizada pela grande quantidade de rochas, qual seria a melhor solução para tratamento de esgoto sanitário individual neste loteamento?

Nos casos onde não há destinação adequada aos esgotos, estes passam a 
escoar a céu aberto, poluindo o solo e contaminando as águas superficiais e subterrâneas, constituindo perigosos disseminantes de doenças (GUIA DO PROFISSIONAL EM TREINAMENTO, 2008). Para tanto, o objetivo geral deste trabalho foi propor uma solução para tratamento individual de esgoto sanitário no Loteamento Mantovani, na cidade de Caçador/SC. Deste modo, teve como objetivos específicos:

a. Apresentar a importância dos sistemas de tratamento de esgoto;

b. Descrever os sistemas individuais de esgoto sanitário e sua relevância;

c. Apresentar as características do loteamento em estudo;

d. Realizar ensaio de percolação no loteamento em estudo;

e. Dimensionar sistemas individuais de esgoto sanitário.

A metodologia utilizada para o desenvolvimento deste trabalho foi a pesquisa bibliográfica, buscando-se referencial teórico que pudesse nortear o problema abordado, além da aplicação em um estudo de caso.

\section{DESENVOLVIMENTO}

O desenvolvimento do trabalho é composto pelo referencial teórico sobre o tema abordado, além dos materiais e métodos essenciais para aplicação do tema proposto.

\subsection{ESGOTO SANITÁRIO}

A NBR 9648 (ABNT, 1986, p. 01), define o esgoto sanitário como "despejo líquido constituído de esgotos doméstico e industrial, água de infiltração e a contribuição pluvial parasitária". O termo esgoto é utilizado para caracterizar os despejos provenientes das diversas modalidades de origem e utilização das águas, provenientes do uso doméstico, comercial, industrial, de utilidades públicas, áreas agrícolas, de superfície, infiltração, pluviais e demais efluentes sanitários (JORDÃO; PESSOA, 1995).

Segundo Dacach (1990), é de conhecimento amplo que diversas doenças são transmitidas pelas excretas humanas, que são lançadas à superfície do terreno ainda em muitas regiões, onde sua exposição direta causa perigo à saúde da 
população. Assim, as águas contaminadas por esgotos urbanos são causadoras de doenças bactericidas, transmitidas aos seres humanos através da ingestão ou contato com a pele (MAGOSSI; BONACELLA, 2003).

\subsection{SISTEMAS INDIVIDUAIS DE TRATAMENTO DE ESGOTO}

A NBR 13969 (ABNT, 1997) define que um sistema local de tratamento de esgotos é aquele onde as distâncias entre as fontes geradoras de esgotos, seu tratamento e disposição final são próximas entre si, normalmente dispensando o uso de rede coletora extensa, coletor-tronco, poços de visita, emissários, elevatórias etc.

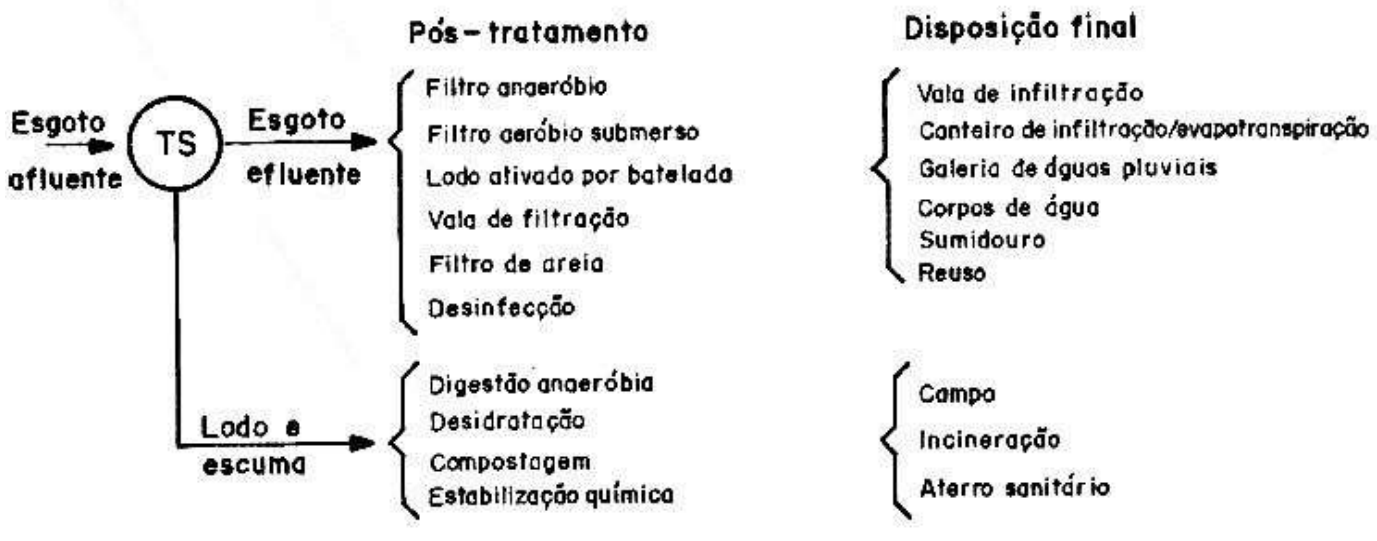

Obs: Pode haver combinaçöes das altemativas

Figura 1 - Alternativas para tratamento e disposição de esgoto sanitário Fonte: NBR 13969 (ABNT, 1997)

Em decorrência das necessidades de saneamento básico efetivo em áreas não englobadas por sistema de rede coletora e tratamento de esgotos de porte, da proteção do manancial hídrico e do meio ambiente, é imprescindível a oferta de alternativas técnicas viáveis para proceder ao tratamento e disposição do efluente(NBR 13969, ABNT, 1997). A Figura 1 apresenta um esquema geral das alternativas para tratamento e disposição de efluentes em sistemas individuais, utilizando-se como princípio básico o tratamento via tanque séptico (NBR 13969, ABNT, 1997). 


\subsection{CAPACIDADE DE ABSORÇÃO DO SOLO}

Em função dos diversos métodos de disposição do efluente de tanque séptico, é necessário o conhecimento da capacidade de absorção do solo.

Para determinação das características de absorção do solo, o método mais comum é a determinação da permeabilidade em função da textura do solo, ou seja, das proporções de areia, silte e argila existentes. Entretanto, o método aconselhável é o ensaio de percolação, para que se estime quantitativamente a capacidade de absorção dos solos (JORDÃO; PESSOA, 1995). A NBR 13969 (ABNT, 1997) lista dois ensaios, de caráter simples, que são instrumentos úteis para avaliação da infiltração dos solos quando utilizados em conjunto com os ensaios de tato e visual do solo. Ambos podem ser realizados no local onde serão instalados sumidouro ou vala de infiltração.

\subsection{CARACTERÍSTICAS DO LOTEAMENTO EM ESTUDO}

A Lei n 6.766 (BRASIL, 1979, p. 1) considera loteamento como "a subdivisão de gleba em lotes destinados à edificação, com abertura de novas vias de circulação, de logradouros públicos ou prolongamento, modificação ou ampliação das vias existentes". O Loteamento Mantovani está localizado no prolongamento da Rua Amazonas, Bairro Santa Catarina, no Município de Caçador/SC, e suas coordenadas geográficas centrais são: $26^{\circ} 45^{\prime} 24,18^{\prime \prime}$ S; e $51^{\circ} 01^{\prime} 08,79^{\prime \prime} \mathrm{O}$. Sua área loteável é de $38.114,20 \mathrm{~m}^{2}$, dividida em seis quadras que compõem aproximadamente 81 lotes, cujas áreas variam entre $250,00 \mathrm{~m}^{2}$ a $310,00 \mathrm{~m}^{2}$. Trata-se de loteamento destinado à implantação de residências uni e multifamiliares.

A escolha do loteamento em questão como objeto de estudo para fins didáticos deu-se pelo fato do mesmo possuir características singulares quanto ao subsolo. Em diversos pontos do loteamento, de acordo com laudo de sondagem existente, é possível observar a existência de grande quantidade de rochas subterrâneas próximas à superfície. Dentre os pontos existentes, o destacado como crítico possui solo argiloso plástico com matéria orgânica entre a superfície e -0,40m; solo argiloso escuro, altamente compacto, sem ocorrência de água, entre -0,40m e $-1,57 m$; e em -1,57 é encontrada rocha basáltica.

Em função da rede coletora de esgoto executada no local não possuir 
condições de ser posta em funcionamento - devido à inexistência de coletor municipal próximo ao loteamento, que destinaria o efluente à uma Estação de Tratamento de Esgoto (ETE) -, torna-se necessária a adoção de formas individuais de tratamento e disposição do efluente doméstico produzido pelos moradores do local.

\subsection{APRESENTAÇÃO, ANÁLISE DOS DADOS E RESULTADOS}

Destinado à apresentação dos dados recolhidos durante a realização do trabalho, das considerações e dos resultados obtidos.

\subsubsection{Ensaio de Percolação}

No dia 27 de Agosto de 2017, realizou-se a escavação de uma cava de 0,70m, com diâmetro de 0,30m, no ponto indicado como crítico pelo laudo de sondagem (Figura 2).

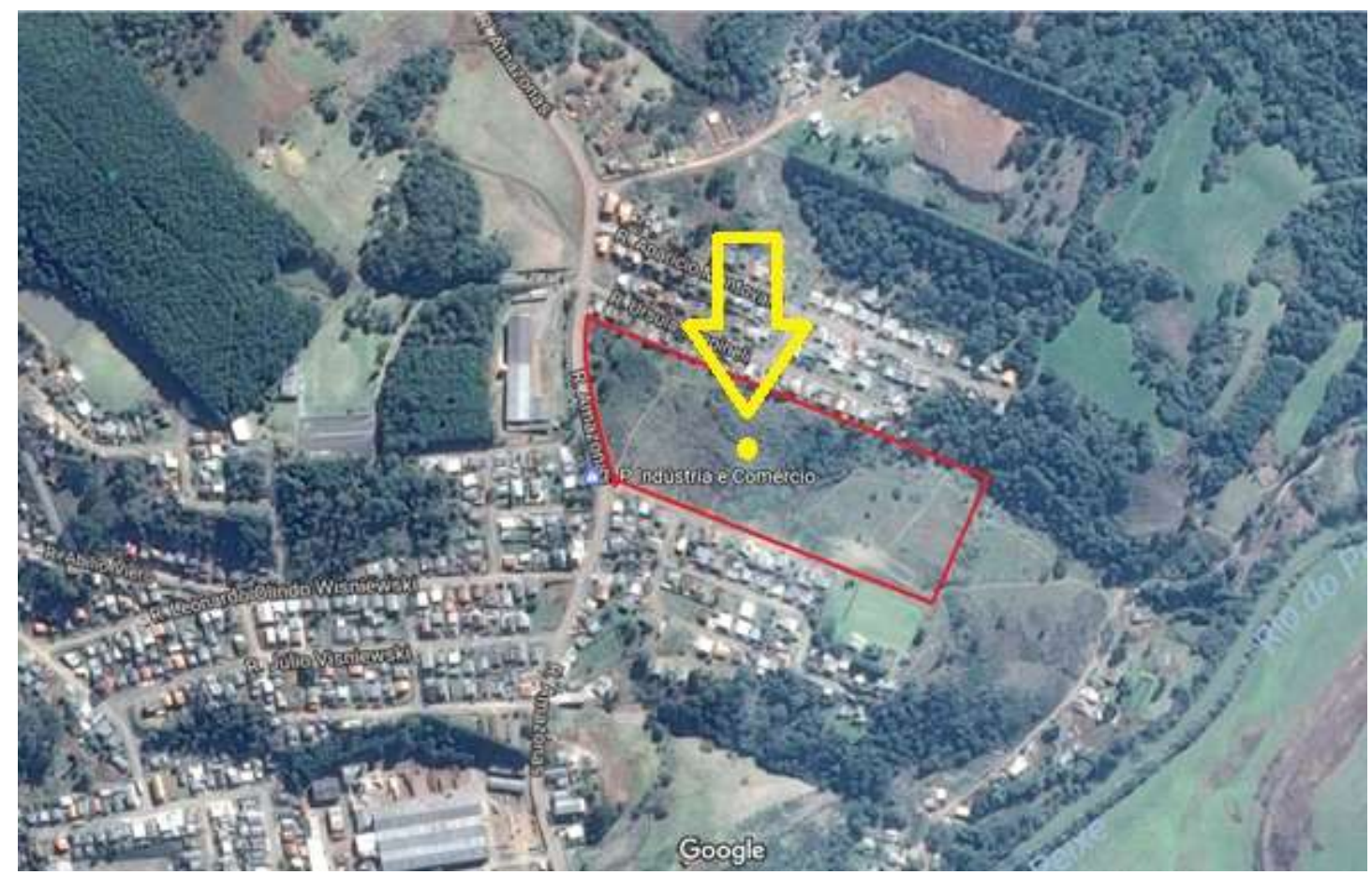

Figura 2 - Ponto de realização do ensaio de percolação no Loteamento Mantovani Fonte: Adaptado de Google Maps (2017)

Como recomendado pela NBR 13969 (ABNT, 1997), o fundo da cava foi 
preenchido com pedra brita (Figura 3) e promoveu-se a saturação da cava, adicionando-se 0,30m de água limpa. O nível da água deveria ser mantido durante quatro horas, para então dar-se início ao teste de percolação.

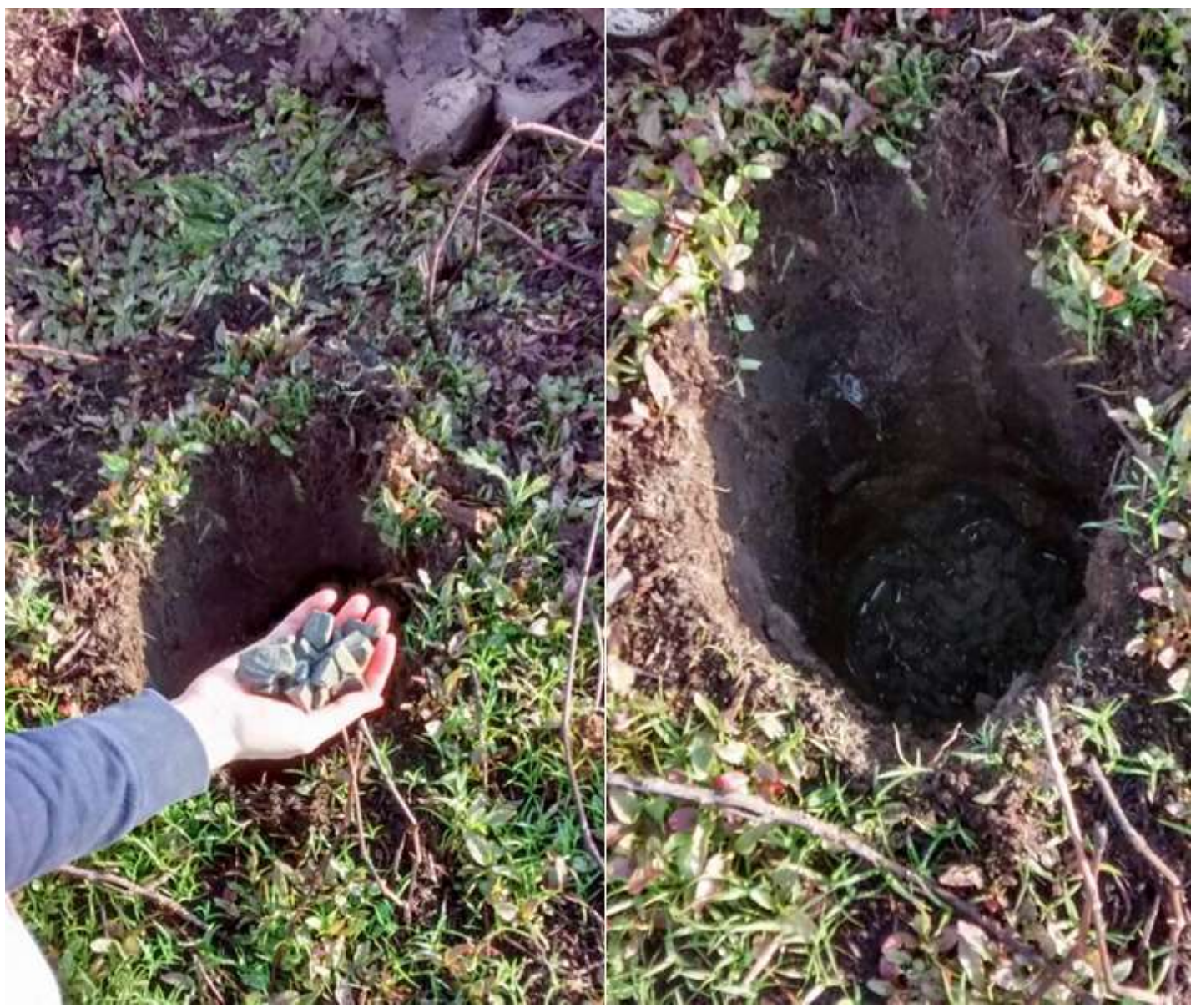

Figura 3 - Ensaio de percolação - preenchimento da cava com pedra brita Fonte: O próprio autor

Entretanto, após 3 horas de realização do enchimento com água, o nível aumentou $3 \mathrm{~cm}$ da marca inicial, de $30 \mathrm{~cm}$, ao contrário do esperado, que seria infiltrar no terreno (Figura 4). Assim, não se pôde dar continuidade ao teste.

Além disso, foi possível observar que o executor do loteamento está efetuando aterro de aproximadamente 2,00m de altura em grande parte da região caracterizada como argilosa pelas sondagens (Figura 5), de modo a nivelar o terreno e possibilitar a adoção de algum modo de disposição final do efluente sanitário das 
residências. Deste modo, como a área onde o ponto está locado será aterrada, os resultados obtidos em testes de percolação na topografia natural não oferecem real aplicação.

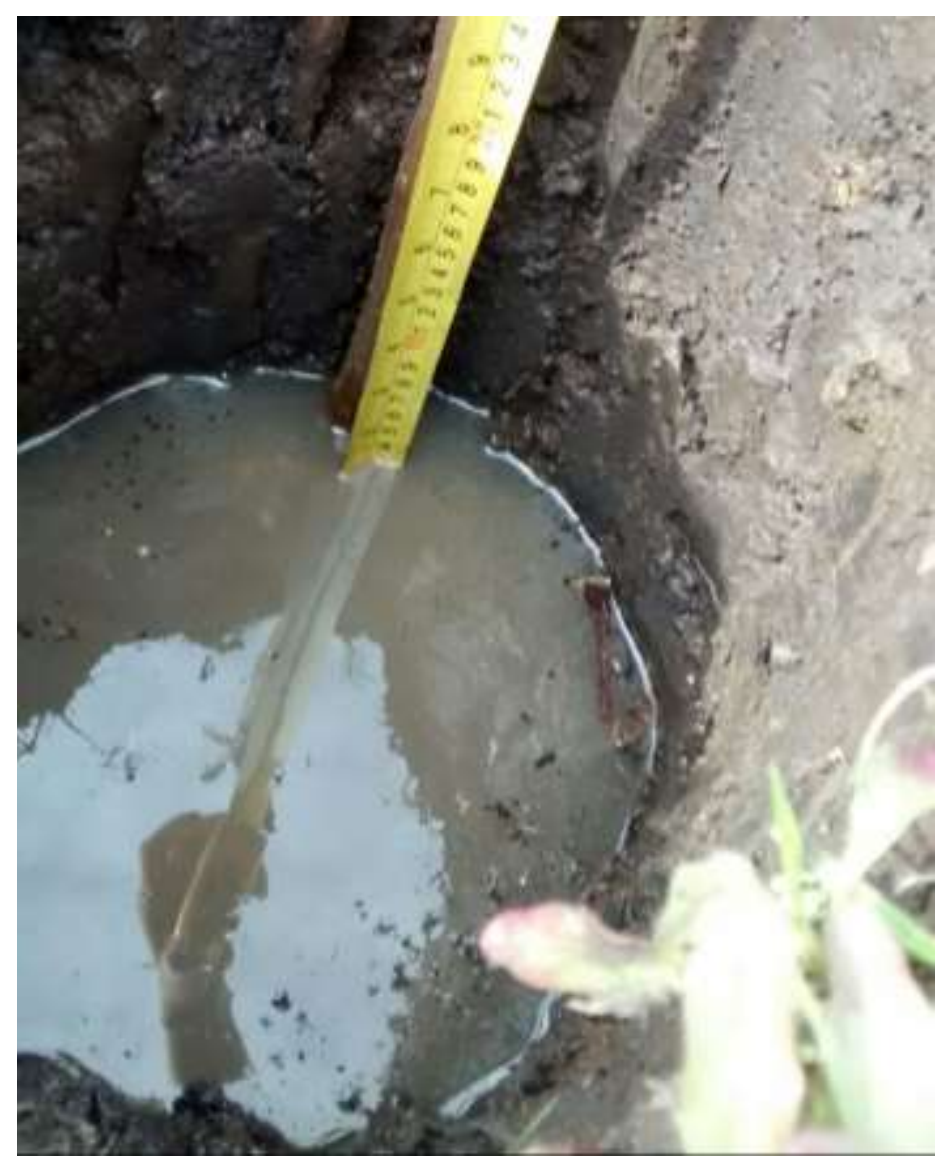

Figura 4 - Cava após 3 horas de saturação

Fonte: O próprio autor 


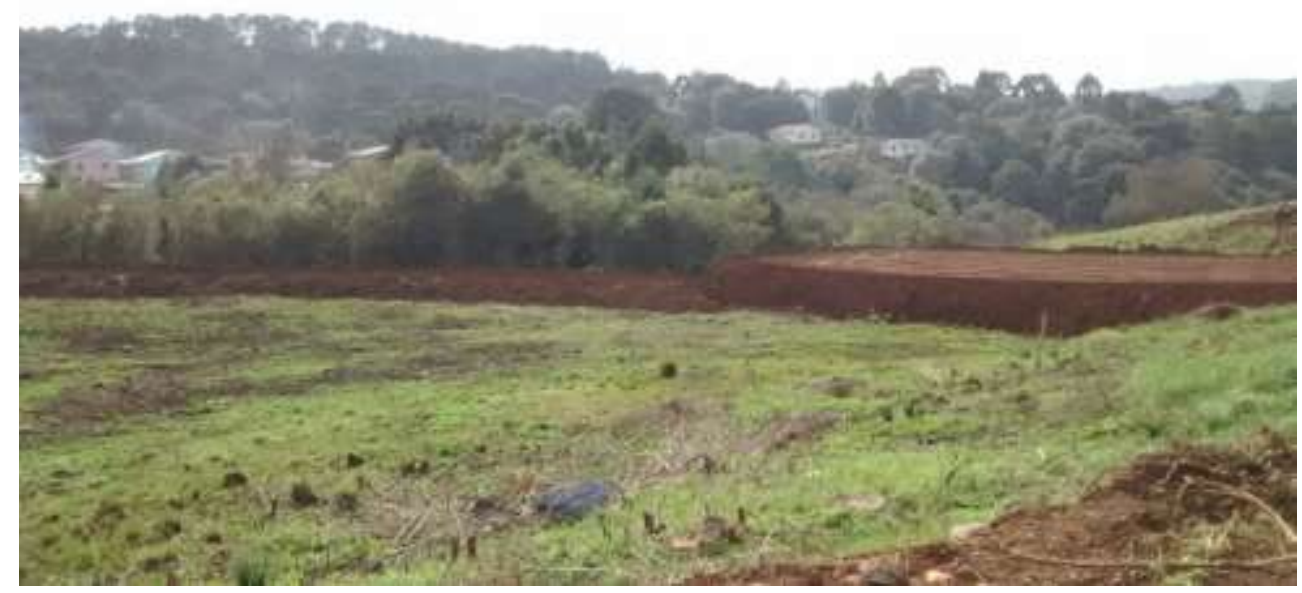

Figura 5 - Aterro parcialmente executado na região do Loteamento

Fonte: O próprio autor

\subsubsection{Dimensionamento do Sistema de Tratamento Individual de Esgoto}

O dimensionamento dos elementos constituintes do sistema individual de tratamento dos efluentes sanitários foi realizado de acordo com a NBR 7229 (ABNT, 1993) e NBR 13969 (ABNT, 1997), que tratam, respectivamente, de tanque séptico e de unidades de tratamento complementar e disposição final dos efluentes, além da bibliografia que aborda o assunto.

O Loteamento Mantovani será destinado à execução de edificações residenciais. Desta forma, optou-se pela proposição de solução para uma residência unifamiliar padrão Normal (R1-N), com três quartos, sendo um suíte com banheiro, banheiro social, sala, cozinha, circulação, área de serviço com banheiro e varanda, com área aproximada de $110 \mathrm{~m}^{2}$.

\subsubsection{Tanque séptico}

Tanque séptico é definido pela NBR 7229 (ABNT, 1993) como unidade de fluxo horizontal destinada ao tratamento de esgotos por processos de sedimentação, flotação e digestão.

Para a residência padrão Normal com 3 dormitórios, foram adotados anéis 
de concreto pré-moldado, com diâmetro de 1,50m e 0,60m de altura.

Neste caso, segundo dados da NBR 7229 (ABNT, 1993), tem-se que:

$\mathrm{N}=2$ pessoas $* 3$ dormitórios $=6$ pessoas

$\mathrm{C}=130$ litros/habitantes $\mathrm{x}$ dia

$T=0,92$ dia

$\mathrm{K}=$ intervalo de limpeza de 1 ano $=94$ dias

Lf $=1$ litro/pessoa.dia

Assim:

$$
V=1000+N(C . T+K . L f)
$$

$V=1000+6(130.0,92+94.1)$

$V=2281,6$ litros

As dimensões do tanque cilíndrico são definidas através do seguinte:

Hu (Altura útil)= 1,20m (mínima) e 2,20m (máxima)

$\varnothing$ interno mínimo $=1,10 \mathrm{~m}$

$$
\begin{aligned}
& \text { Vútil }=\left(\frac{\pi \cdot \phi^{2}}{4}\right) \cdot H u \quad \therefore \quad \varnothing=\sqrt{\frac{V \text { útil } \cdot 4}{\pi \cdot H u}} \\
& \varnothing=\sqrt{\frac{2,30 \cdot 4}{\pi \cdot 1,50}} \\
& \varnothing=1,39 \cong 1,50 m
\end{aligned}
$$

A altura útil é acrescida de $0,30 \mathrm{~m}$, para disposição dos tubos de entrada e saída do efluente. Desta forma:

$H$ final $=1,50+0,30=1,80 m$

Assim, para definição da quantidade de anéis de concreto pré-moldado: 
№ anéis $=1,80 / 0,60=3$ anéis

Deste modo, adotou-se tanque séptico com 3 anéis pré-moldados de 0,60m totalizando $1,80 \mathrm{~m}$ de altura, e diâmetro de 1,50m.

\subsubsection{Filtro anaeróbio de fluxo ascendente}

O filtro anaeróbio é um reator biológico com esgoto em fluxo ascendente, dotado de uma câmara inferior vazia e uma câmara superior preenchida de meio filtrante submerso, onde atuam micro-organismos anaeróbios e facultativos, responsáveis pela estabilização da matéria orgânica (NBR 13969, ABNT, 1997). Em relação ao tamanho do filtro anaeróbio, foram adotados anéis de concreto prémoldado com 1,30m de diâmetro e 0,50m de altura.

Tem-se, pela NBR 13969 (ABNT, 1997):

$N=3$

C $=130$ litros $\times$ habitantes $/$ dia

$T=1,08$ dias

Assim:

$V u=1,6$ N.C.T

$V u=1,6 \cdot 6 \cdot 130 \cdot 1,08$

$\mathrm{Vu}=1347,84$ litros

$\mathrm{Vu}=1400$ litros

A altura útil do filtro anaeróbio é fixada em 1,20 metros. Assim:

$$
\begin{aligned}
& r=\sqrt{\frac{V}{\pi \cdot h}} \\
& r=\sqrt{\frac{1,400}{\pi \cdot 1,20}}=0,61 \mathrm{~m}
\end{aligned}
$$




\section{Calcula-se, então, o diâmetro de cada anel: \\ $D=0,61 \mathrm{~m} \times 2=1,22 \mathrm{~m}$

Desta forma, adota-se filtro anaeróbio com 3 anéis pré-moldados de 1,30m de diâmetro e 0,50m de altura, totalizando 1,50m de altura total.

\subsubsection{Vala de infiltração}

É definida pela NBR 13969 (ABNT, 1997) como uma vala escavada no solo, preenchida com meios filtrantes e dotada de tubos de distribuição de esgoto e de coleta de efluente filtrado, cujo objetivo é a remoção de poluentes através de ações físicas e biológicas sob condições essencialmente aeróbias.

Neste caso, segundo a NBR 13969 (ABNT, 1997):

$\mathrm{Q}=\mathrm{N} . \mathrm{C}=780 \mathrm{litros} / \mathrm{dia}$

$\mathrm{Ci}=60$

Assim, de acordo com Jordão e Pessoa (1995):

$$
\begin{aligned}
& A=\frac{Q}{C i} \\
& A=\frac{780}{60}=13 \mathrm{~m}^{2}
\end{aligned}
$$

Considerando a largura da vala de 0,50m, tem-se que:

$13 \mathrm{~m}^{2} / 0,50 m=26$ metros

$26 / 4$ valas $=6,5 \mathrm{~m}$

Considerando a logística de alternância imposta pela NBR 13969 (ABNT, 1997), devem ser acrescidas duas valas ao resultado obtido. Assim, serão necessárias 6 valas com aproximadamente 6,50 metros de comprimento cada, para residência padrão normal com três dormitórios.

\subsubsection{Sumidouro}

O sumidouro é definido pela NBR 13969 (ABNT, 1997) como a unidade de depuração e de disposição final do efluente oriundo de tanque séptico, sendo 
verticalizado em relação à vala de infiltração. Em relação às características do sumidouro, utilizou-se a unidade retangular executada in loco, considerando-se somente as paredes como área permeável. Esta característica foi adotada em função da existência de material argiloso com afluência de água abaixo do aterro executado na área, o que poderia dificultar a operação de sumidouros com fundo permeável.

Neste caso, segundo a NBR 13969 (ABNT, 1997):

$\mathrm{Q}=\mathrm{N} \cdot \mathrm{C}=780$ litros $/ \mathrm{dia}$

$\mathrm{Ci}=60$

Assim, de acordo com Jordão e Pessoa (1995):

$$
\begin{aligned}
& A=\frac{Q}{C i} \\
& A=\frac{780}{60}=13 \mathrm{~m}^{2}
\end{aligned}
$$

O cálculo da altura do sumidouro é realizado através das faces disponíveis para infiltração. Assim, considerando-se apenas as laterais de um sumidouro cilíndrico, com diâmetro estipulado de 1,50m:

$$
\begin{gathered}
A=(2 \cdot \pi \cdot r \cdot h) \quad(11) \\
13=(2 \cdot \pi \cdot 0,75 \cdot h) .: 13=4,71 \cdot h \\
h=2,75 m .: 2,75 / 0,60 m=4,59 \text { anéis }
\end{gathered}
$$

Caso fosse utilizado o sumidouro cilíndrico, seria necessária a altura total de 3 metros, tornando inviável sua utilização neste caso. Assim, é possível diminuir a altura necessária para instalação de um sumidouro construindo-o com geometria retangular, moldado in loco. Desta forma, adotando-se sumidouro com 3,50m de comprimento, 1,60 m de largura e 1,30m de altura útil, adotando-se as paredes como área permeável, tem-se como área de infiltração disponível:

$$
\begin{aligned}
& \text { A infiltração }=(3,5 * 1,3 * 2)+(1,6 * 1,3 * 2) \\
& \text { A infiltração }=13,3 \mathrm{~m}^{2}>13 \mathrm{~m}^{2}, \text { ok. }
\end{aligned}
$$

Adota-se, portanto, sumidouro moldado in loco com 3,5m de comprimento, $1,60 \mathrm{~m}$ de largura e $1,80 \mathrm{~m}$ de altura total $(1,30 \mathrm{~m}$ de altura útil acrescido de $0,50 \mathrm{~m}$ 
para disposição do tubo de entrada.

\subsubsection{Dimensões Finais Obtidas}

De acordo com o dimensionamento exposto anteriormente, obteve-se, como medidas finais para cada equipamento determinado:

Tabela 1 - Dimensões finais - Tanque Séptico

Equipamento sanitário

Dimensões obtidas

\begin{tabular}{ll}
\hline Tanque séptico & $h=1,80 m-3$ anéis $0,60 \mathrm{~m}, \varnothing=1,50 \mathrm{~m}$ \\
\hline Filtro anaeróbio & $\mathrm{h}=1,50 \mathrm{~m}-3$ anéis $0,50 \mathrm{~m}, \varnothing=1,30 \mathrm{~m}$ \\
\hline Vala de Infiltração & 6 valas com $6,50 \mathrm{~m} \times 0,50 \mathrm{~m} \times 0,50 \mathrm{~m}$ \\
\hline Sumidouro & $\mathrm{h}=1,80 \mathrm{~m}$, base $=3,50 \mathrm{~m} \times 1,60 \mathrm{~m}$
\end{tabular}

Fonte: O próprio autor

\section{CONCLUSÃO}

A manutenção de condições adequadas para preservação da saúde na sociedade é fator de importância primária. Desta forma, as ações de saneamento, especialmente as inclusas no ramo de esgotamento sanitário, devem ser tratadas como prioridades em projetos de construção civil.

O projeto de sistemas de esgotamento sanitário em obras residenciais, assim como nas diversas outras em que é aplicado, deve seguir padrões estabelecidos em Normas Brasileiras para que sejam efetuados o tratamento e a disposição final adequados, buscando o menor impacto possível ao meio em que estão inseridos. Em loteamentos residenciais, como o caso abordado neste estudo, além da busca por métodos que causem menor degradação ambiental, buscam-se métodos de tratamento e disposição do esgoto simplificados, com o menor custo de manutenção e operação possível.

O município de Caçador é caracterizado pela predominância das soluções individuais de tratamento do esgoto, com poucas áreas contando com rede coletiva. O Loteamento Mantovani, localizado no prolongamento da Rua Amazonas, no Bairro Santa Catarina, mesmo possuindo rede coletora "em espera", deverá contar com soluções individuais de tratamento, que atendam as características específicas deste loteamento, como subsolo rochoso próximo à superfície. 
Dentre as opções de sistemas individuais de esgotamento sanitário existentes, a utilização do tanque séptico é unânime. A pesquisa bibliográfica permitiu demonstrar que o efluente oriundo do tanque séptico pode ser destinado para filtros anaeróbios, valas de filtração ou infiltração, sumidouros, filtros de areia, entre outros métodos de disposição.

Com os dados disponíveis, efetuou-se a determinação e dimensionamento dos métodos considerados adequados para as condições específicas encontradas no loteamento. Obteve-se, como solução para o caso em estudo, o tratamento do efluente através de tanque séptico, o pós-tratamento em filtro anaeróbio de fluxo ascendente, e a disposição final do mesmo utilizando-se valas de infiltração ou sumidouro. O ensaio de percolação realizado, em função da afluência de água na cava executada, não possibilitou a obtenção de resultados palpáveis.

As unidades dimensionadas são características à uma residência de padrão Normal com 3 quartos. Em quaisquer casos onde as residências possuírem menos dormitórios do que o exemplo adotado ou forem caracterizadas como padrão de construção Baixo, podem ser adotadas as mesmas formas de dimensionamento. Deve-se, porém, analisar as opções oferecidas neste trabalho e determinar as opções adequadas a cada caso de acordo com fatores como: dimensão do lote em questão, técnicas de construção e operação dos equipamentos sanitários.

Diante do exposto, considerou-se que, com a adoção destas unidades, o efluente produzido pelos residentes do loteamento não ocasionará prejuízos ambientais até que possa ser efetivamente coletado e destinado a uma estação de tratamento de esgotos.

\section{REFERÊNCIAS}

AISSE, Miguel Mansur. Sistemas Econômicos de Tratamento de Esgotos Sanitários. Rio de Janeiro: ABES, 2000. 192 p.

ANDRADE NETO, Cícero Onofre de. Sistemas Simples para Tratamento de Esgotos Sanitários: Experiência Brasileira. Rio de Janeiro: Associação Brasileira de Engenharia Sanitária e Ambiental (ABES), 1997.

ASSOCIAÇÃO BRASILEIRA DE NORMAS TÉCNICAS. NBR 7229: Projeto, construção e operação de sistemas de tanques sépticos. Rio de Janeiro, 1993. 
ASSOCIAÇÃO BRASILEIRA DE NORMAS TÉCNICAS. NBR 9648: Estudo de concepção de sistemas de esgoto sanitário. Rio de Janeiro, 1986.

ASSOCIAÇÃO BRASILEIRA DE NORMAS TÉCNICAS. NBR 13969: Tanques sépticos Unidades de tratamento complementar e disposição final dos efluentes líquidos: Projeto, construção e operação. Rio de Janeiro, 1997.

BRASIL. Lei n. 6.766, de 19 de Dezembro de 1979. Dispõe sobre o Parcelamento do Solo Urbano e dá outras Providências. Disponível em:

<http://www.planalto.gov.br/ccivil_03/leis/L6766.htm>. Acesso em: 16 maio 2017.

GUIA DO PROFISSIONAL EM TREINAMENTO. Esgotamento sanitário: operação e manutenção de redes coletoras de esgotos. Brasília: Ministério das Cidades, 2008.

JORDÃO, Eduardo Pacheco; PESSOA, Constantino Arruda. Tratamento de Esgotos Domésticos. 3. ed. Rio de Janeiro: Associação Brasileira de Engenharia Sanitária e Ambiental (ABES), 1995.

MAGOSSI, Luiz Roberto; BONACELLA, Paulo Henrique. Poluição das Águas. 2. ed. São Paulo: Editora Moderna, 2003. 